\title{
Substituent Effects on the Energetics and Aromaticity of Aminomethylbenzoic Acids
}

\author{
Carlos F. R. A. C. Lima, ${ }^{\dagger}$ Lígia R. Gomes,,${ }^{\ddagger}$ and Luís M. N. B. F. Santos $*, \dagger$ \\ Centro de Investigação em Química, Departamento de Química, Faculdade de Ciências, Universidade do \\ Porto, $R$ Campo Alegre 687, 4169-007 Porto, Portugal, and CIAGEB, Faculdade de Ciências da Saúde da \\ UFP, Universidade Fernando Pessoa, R Carlos da Maia 296, 4200-150 Porto, Portugal
}

Received: April 21, 2007; In Final Form: July 11, 2007

\begin{abstract}
The standard $\left(p^{0}=0.1 \mathrm{MPa}\right)$ molar enthalpies of combustion of six aminomethylbenzoic acids were measured at $T=298.15 \mathrm{~K}$ by static bomb calorimetry. With these values, the standard molar enthalpies of formation in the crystalline state were obtained. Combining these results with the standard molar enthalpies of sublimation, the standard molar enthalpies of formation in the gaseous phase were derived. For the 10 possible isomers, the obtained experimental results were compared to and correlated with the relative stability obtained by ab initio calculations at the B3LYP/6-311++G(d,p) level of theory. Seeking a better understanding of the aromatic behavior and energetics of aminomethylbenzoic acids in the gas phase, calculations of NICS values, HOMA indices, and dihedral angles between the aromatic carbon and the amino group, $\Phi(\mathrm{Ar}-\mathrm{NHH})$, were also performed computationally. The significant differences observed in the energetics, as well as in the NICS values, HOMA indices, and $\Phi(\mathrm{Ar}-\mathrm{NHH})$ dihedral angles for these 10 isomers suggest a strong dependency on the identity and relative position of the three substituents on the benzene ring. This study points out a marked tendency for a decrease of the ring aromaticity, accompanied by an increase in the respective system stability, as the conjugation between the substituents becomes more extensive.
\end{abstract}

\section{Introduction}

Aminobenzoic acids and its derivatives are unnatural amino acids used as building blocks in polymeric synthesis, especially for conducting polymers, ${ }^{1,2}$ peptides, and peptidomimetic molecules. Aminomethylbenzoic acids have been incorporated as hydrophobic spacers in peptidomimetic molecules used for the inhibition of enzymatic activity in the catabolism of oncoproteic products. ${ }^{3,4}$ The study of the aromatic behavior of the monomers is relevant to understanding and predicting the properties of the corresponding polymers. In this work, the energetics of aminomethylbenzoic acids in the gaseous phase is explored by performing an experimental and computational thermochemical study of the possible isomers of this series. The aim is to achieve a deeper knowledge of the subject of aromaticity and substituent effects.

Aminomethylbenzoic acids are trisubstituted benzene compounds with the general structure shown in Figure 1. Within the text, aminomethylbenzoic acids will generally be referred to as $X \mathrm{a}-Y \mathrm{~m}-\mathrm{BA}$, where $X$ represents the position of the amino group a, Y represents the position of the methyl group $\mathrm{m}$, and BA denotes benzoic acid.

Aromaticity is a complex and multidimensional physicochemical phenomenon that greatly affects many molecular properties such as magnetism, reactivity, and relative energy. The nucleus-independent chemical shift (NICS) is a generally accepted and widely used criterion for measuring aromaticity since its introduction by Schleyer et al. ${ }^{5}$ It is defined as the negative value of the absolute magnetic shielding computed at any point of interest in the molecule, usually at the ring

* Corresponding author. Tel.: +351 226082836. Fax: +351 226082959. E-mail: lbsantos@fc.up.pt.

$\dagger$ Universidade do Porto.

$\div$ Universidade Fernando Pessoa.

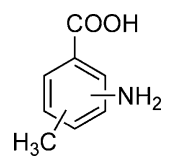

Figure 1. General structural formula for the isomers of aminomethylbenzoic acid.

centers. It is therefore related to the magnetic consequences of aromaticity. Recently, Stanger ${ }^{6}$ proposed a method based on scanning NICS values over a distance and separating them into in-plane and out-of-plane components, suggesting the out-ofplane eigenvalue of the chemical shift tensors as a more meaningful determination of the aromatic character. It was also observed, by the same author, that the general shapes of the curves describing the isotropic NICS values as functions of the probe's distance are governed by the out-of-plane component in the aromatic systems.

The harmonic oscillator model of aromaticity (HOMA) was introduced by Krygowski et al. ${ }^{7}$ and is directly related to the influence of aromaticity on molecular geometry. In the present work, both NICS-scan values and HOMA indices for the 10 possible isomers of aminomethylbenzoic acid and related lesssubstituted benzenes were calculated by DFT at the B3LYP/6$311++\mathrm{G}(\mathrm{d}, \mathrm{p})$ level of theory.

The effect of substituents on the benzene ring is strongly correlated with energetic aspects of the molecule, including aromaticity. A recent work on this subject, concerning monosubstituted benzenes, indicates that the presence of only one substituent does not significantly affect the aromaticity of the benzene ring. ${ }^{8,9}$ In the present work, the simultaneous effects of three substituents $\left(-\mathrm{COOH},-\mathrm{NH}_{2}\right.$, and $\left.-\mathrm{CH}_{3}\right)$ on the energetics and aromaticity of the benzene ring has been explored. Classically, substituents can interact with the benzene framework by inductive (related to the $\sigma$ component of chemical bonds) and mesomeric (related to the $\pi$ electronic cloud of the 
molecule) effects. The presence of more than one substituent can induce a variety of phenomena that are hard to describe and systematize. Conjugation is directly related to $\pi$ electronic density and, therefore, strongly related to aromaticity. The extent to which a substituent is conjugated with the aromatic framework can alter aromaticity as well as relative molecular stability. Aminomethylbenzoic acids are interesting compounds because the benzene ring simultaneously bears a $\pi$-acceptor $(-\mathrm{COOH})$, a $\pi$-donor and $\sigma$-acceptor $\left(-\mathrm{NH}_{2}\right)$, and a $\sigma$-donor and weak $\pi$-donor by hyperconjugation $\left(-\mathrm{CH}_{3}\right)$.

The standard molar enthalpies of formation in the crystalline state of the six commercially available aminomethylbenzoic acids, at $T=298.15 \mathrm{~K}$, were determined by static bomb combustion calorimetry and, combined with the standard molar enthalpies of sublimation (determined previously by Monte and Hillesheim ${ }^{10}$ ), allowed for the derivation of the standard molar enthalpies of formation in the gaseous state at the same temperature. Combined with the information obtained by computational chemistry, the experimental results were compared and analyzed altogether.

\section{Experimental Section}

Purification and Characterization of the Compounds. The aminomethylbenzoic acids: 2-amino-3-methylbenzoic acid (2a3m-BA, CAS no. 4389-45-1), 2-amino-5-methylbenzoic acid (2a-5m-BA, CAS no. 2941-78-8), 2-amino-6-methylbenzoic acid (2a-6m-BA, CAS no. 4389-50-8), 3-amino-2-methylbenzoic acid (3a-2m-BA, CAS no. 52130-17-3), 3-amino-4-methylbenzoic acid (3a-4m-BA, CAS no. 2458-12-0), and 4-amino-3methylbenzoic acid (4a-3m-BA, CAS no. 2486-70-6) were obtained from Sigma-Aldrich and purified by repeated sublimation in vacuum. The purity of the samples was systematically verified by gas chromatography (using an HP 4890 apparatus equipped with an HP-5 column, cross-linked, 5\% diphenyl and 95\% dimethylpolysiloxane) and confirmed by HPLC using a Merck Hitachi (LaChrom) apparatus with an L-7420 UV-vis detector, an L-7100 pump, a D-7000 interface, and a C18 reverse-phase column. The eluent used was a mixture of $\mathrm{CH}_{3-}$ $\mathrm{OH} / \mathrm{H}_{2} \mathrm{O} 30 / 70(\mathrm{v} / \mathrm{v})$ at an isocratic flow rate of $0.8 \mathrm{~mL} / \mathrm{min}$. The UV-vis detector was operated at $254 \mathrm{~nm}$ in all runs. Retention times varied from $9.03 \mathrm{~min}$ (3a-2m-BA) to $27.87 \mathrm{~min}$ (2a-5m-BA). During the combustion experiments, the sample purity and combustion completeness were supported by a $\mathrm{CO}_{2}$ recovery analysis.

Combustion Calorimetry. The enthalpies of combustion were measured in an isoperibol static bomb combustion calorimeter with a twin-valve bomb with an internal volume of $0.290 \mathrm{dm},{ }^{3}$ formerly used at the National Physical Laboratory, Teddington, U.K., ${ }^{11}$ and in Manchester, U.K. ${ }^{12}$ This calorimeter was transferred from Manchester to Porto, Portugal, and was used mainly as previously described, ${ }^{11,12}$ although a few changes in technique, due to different auxiliary equipment, were applied.

From a weighed acrylic vessel, water was added to the calorimeter, and for each experiment, a correction to the energy equivalent for the deviation from a mass of $2900.0 \mathrm{~g}$ of water added was taken into account. Calorimetric temperatures were measured to $1 \times 10^{-4} \mathrm{~K}$ with a S10 four-wire calibrated ultrastable thermistor (Thermometrics, standard serial no. 1030) and recorded via a nano-ohm meter (Hewlett-Packard model 34420A) interfaced to a IBM PC computer programmed to compute the adiabatic temperature change using the program LABTERMO. ${ }^{13,14}$ Temperature measurements were automatically collected every $10 \mathrm{~s}$, and the initial temperature of the combustion experiments was very close to $298.15 \mathrm{~K}$.
The energy equivalent of the calorimeter was determined from the combustion of benzoic acid (Calorimetric Standard NIST 39j), having a massic energy of combustion under bomb conditions of $-(26434.0 \pm 3.0) \mathrm{J} \cdot \mathrm{g}^{-1}$, as previously described. ${ }^{15}$ The electrical energy for ignition was determined from the change in the potential difference across a $1400 \mu \mathrm{F}$ condenser on discharge through a platinum ignition wire. For the cotton thread fuse (empirical formula $\mathrm{CH}_{1.686} \mathrm{O}_{0.843}$ ), the massic energy of combustion was assigned to $\Delta_{\mathrm{c}} u^{\circ}=-16240 \mathrm{~J} \cdot \mathrm{g}^{-1} \cdot{ }^{16}$ Corrections for nitric acid formation were based on -59.7 $\mathrm{kJ} \cdot \mathrm{mol}^{-1}$ for the molar energy of formation of $0.1 \mathrm{~mol} \cdot \mathrm{dm}^{-3}$ $\mathrm{HNO}_{3}(\mathrm{aq})$ from $\mathrm{O}_{2}, \mathrm{~N}_{2}$, and $\mathrm{H}_{2} \mathrm{O}$ (1). ${ }^{17}$

From 11 calibration experiments, the energy equivalent of the calorimeter, $\epsilon$ (calor) $/\left(\mathrm{J} \cdot \mathrm{K}^{-1}\right)$, was found to be $[15553.27 \pm$ $\left.0.91\left(5.85 \times 10^{-3} \%\right)\right]$ for an average mass of water added to the calorimeter of $2900.0 \mathrm{~g}$; the quoted uncertainty refers to the standard deviation of the mean.

Samples in pellet form were ignited in oxygen at a pressure of $3.04 \mathrm{MPa}$, with a volume of $1.00 \mathrm{~cm}^{3}$ of water added to the bomb. The amount of nitric acid was determined by titration against NaHO. The density of each of the six compounds was assumed to be $1.39 \mathrm{~g} \cdot \mathrm{cm}^{-3}$. For each compound, $(\partial u / \partial p)_{T}$, at $T$ $=298.15 \mathrm{~K}$, was assumed to be $-0.2 \mathrm{~J} \cdot \mathrm{g}^{-1} \cdot \mathrm{MPa}^{-1}$, a typical value for organic compounds.

Standard-state corrections were calculated for the initial states by the procedures given by Hubbard et al. ${ }^{18}$ and by Good and Scott. ${ }^{19}$

The relative atomic masses used were those recommended by the IUPAC Commission in $2005 .^{20}$

Computational Thermochemistry. All calculations were performed using density functional theory (DFT). ${ }^{21}$ DFT calculations were performed with the hybrid B3LYP exchange correlation functional. ${ }^{22-24}$ Full geometry optimizations were carried out with the $6-311++\mathrm{G}(\mathrm{d}, \mathrm{p})$ basis set. At the same theoretical level, analytical frequency calculations were performed to ensure true minima $\left(N_{\mathrm{img}}=0\right)$. Zero-point vibrational energies (ZPEs) and enthalpy energy correction $\left(\epsilon_{\mathrm{H}}\right)$ contributions were taken into account in the calculation of the enthalpies of all species at $298.15 \mathrm{~K}$. The scaling factors of 0.9804 and 0.9613 were used for the calculation of the zero-point vibrational energies and fundamental vibrational frequencies, respectively. ${ }^{25}$ Extensive work was done around the relative position and group rotation of the amino, methyl, and carboxylic substituents to locate the absolute minimum energy.

The NICS probes $(\mathrm{Bq})$ were placed up and down from the geometric center of the benzene ring, perpendicular to the average benzene plane, from -2 to $+2 \AA$, in increments of 0.2 $\AA$. The NICS values were calculated for all ghost atoms by the standard GIAO procedure at the B3LYP/6-311++G(d,p) level of theory. The $6-311++\mathrm{G}(\mathrm{d}, \mathrm{p})$ basis set was found to be the minimum-quality basis set needed to satisfactorily derive NICS values. ${ }^{6}$ All theoretical calculations were performed using the Gaussian 03 software package. ${ }^{26}$

The bonds lengths used in the calculations of HOMA indices and dihedral angles formed between the amino group and the aryl carbon, $\Phi(\mathrm{Ar}-\mathrm{NHH})$ were taken from the optimized structures. HOMA indices were calculated using the equation

$$
\begin{aligned}
& \text { HOMA }= \\
& 1-\left[\alpha\left(r_{\text {opt }}-r_{\text {av }}\right)^{2}+\frac{\alpha}{n} \sum\left(r_{\mathrm{av}}-r_{i}\right)^{2}\right]=1-\mathrm{EN}-\mathrm{GEO}
\end{aligned}
$$

where $n$ is the number of bonds taken into account in the summation ( $n=6$ for the case of benzene derivatives), $r_{\mathrm{opt}}$ represents the optimum value of a specific bond length in a 
TABLE 1: Typical Experimental Results ${ }^{a}$ for the Combustion of the Six Aminomethylbenzoic Acids at $T=298.15 \mathrm{~K}$

\begin{tabular}{|c|c|c|c|c|c|c|}
\hline & $2 a-3 m-B A$ & $2 a-5 m-B A$ & $2 a-6 m-B A$ & $3 a-2 m-B A$ & $3 a-4 m-B A$ & $4 a-3 m-B A$ \\
\hline$m(\mathrm{cpd})(\mathrm{g})$ & 0.49432 & 0.42098 & 0.49987 & 0.49590 & 0.46807 & 0.56732 \\
\hline$m^{\prime}$ (fuse) $(\mathrm{g})$ & 0.00233 & 0.00369 & 0.00307 & 0.00291 & 0.00265 & 0.00270 \\
\hline$T_{\mathrm{i}}(\mathrm{K})$ & 298.1504 & 298.1510 & 298.1521 & 298.1508 & 298.1511 & 298.1509 \\
\hline$T_{\mathrm{f}}(\mathrm{K})$ & 299.0788 & 298.9595 & 299.0977 & 299.0847 & 299.0830 & 299.1955 \\
\hline$\Delta T_{\mathrm{ad}}(\mathrm{K})$ & 0.84136 & 0.71918 & 0.85508 & 0.84647 & 0.79766 & 0.96423 \\
\hline$\epsilon_{\mathrm{i}}($ cont $)\left(\mathrm{J} \cdot \mathrm{K}^{-1}\right)$ & 15.02 & 14.92 & 15.02 & 15.02 & 14.98 & 15.11 \\
\hline$\epsilon_{\mathrm{f}}($ cont $)\left(\mathrm{J} \cdot \mathrm{K}^{-1}\right)$ & 15.47 & 15.31 & 15.49 & 15.47 & 15.40 & 15.66 \\
\hline$\Delta m\left(\mathrm{H}_{2} \mathrm{O}\right)(\mathrm{g})$ & 0.4 & -1.3 & -1.5 & 0.9 & 1.8 & -0.2 \\
\hline$-\Delta U(\mathrm{IBP})^{b}(\mathrm{~J})$ & 13100.37 & 11192.73 & 13307.12 & 13181.66 & 12424.48 & 15011.19 \\
\hline$\Delta U\left(\mathrm{HNO}_{3}\right)(\mathrm{J})$ & 22.92 & 19.52 & 23.16 & 24.24 & 22.94 & 24.00 \\
\hline$\Delta U$ (ignition) $(\mathrm{J})$ & 1.20 & 1.20 & 1.19 & 1.20 & 1.19 & 1.20 \\
\hline$\Delta U_{\Sigma}(\mathrm{J})$ & 8.92 & 7.54 & 9.04 & 8.95 & 8.42 & 10.35 \\
\hline$m \Delta_{\mathrm{c}} u^{\circ}$ (fuse) $(\mathrm{J})$ & 37.84 & 59.93 & 49.86 & 47.26 & 43.04 & 43.85 \\
\hline$-\Delta_{\mathrm{c}} u^{\circ}(\mathrm{cpd}).\left(\mathrm{J} \cdot \mathrm{g}^{-1}\right)$ & 26358.61 & 26377.65 & 26454.61 & 26416.79 & 26382.75 & 26319.94 \\
\hline
\end{tabular}

${ }^{a} m$ (cpd) is the mass of compound burned in each experiment, $m^{\prime}$ (fuse) is the mass of the fuse (cotton) used in each experiment, $T_{\mathrm{i}}$ is the initial temperature rise, $T_{\mathrm{f}}$ is the final temperature rise, $\epsilon_{\mathrm{i}}$ (cont) is the energy equivalent of the contents in the initial state, $\epsilon_{\mathrm{f}}$ (cont) is the energy equivalent of the contents in the final state, $\Delta m\left(\mathrm{H}_{2} \mathrm{O}\right)$ is the deviation of the mass of water added to the calorimeter from $2900.0 \mathrm{~g}, \Delta T_{\mathrm{ad}}$ is the corrected temperature rise, $\Delta U(\mathrm{IBP})$ is the energy change for the isothermal combustion reaction under actual bomb conditions, $\Delta U\left(\mathrm{HNO}_{3}\right)$ is the energy correction for nitric acid formation, $\Delta U$ (ignition) is the electric energy for ignition, $\Delta U_{\Sigma}$ is the standard-state correction, $\Delta_{\mathrm{c}} u^{\circ}$ (fuse) is the massic energy of combustion of the fuse (cotton), and $\Delta_{\mathrm{c}} u^{\circ}$ is the standard massic energy of combustion. ${ }^{b} \Delta U$ (IBP) includes $\Delta U$ (ignition).

TABLE 2: Individual Values of the Massic Energy of Combustion, $\Delta_{\mathrm{c}} u^{\circ}$, of the Six Isomers at $T=298.15 \mathrm{~K}\left(p^{\circ}=0.1 \mathrm{MPa}\right)$ and Mean Values Represented by $\left\langle\Delta_{\mathrm{c}} u^{\circ}\right\rangle$

\begin{tabular}{|c|c|c|c|c|c|}
\hline $2 a-3 m-B A$ & $2 \mathrm{a}-5 \mathrm{~m}-\mathrm{BA}$ & $2 \mathrm{a}-6 \mathrm{~m}-\mathrm{BA}$ & $3 a-2 m-B A$ & $3 a-4 m-B A$ & $4 a-3 m-B A$ \\
\hline \multicolumn{6}{|c|}{$\Delta_{\mathrm{c}} u^{\circ}\left(\mathrm{J} \cdot \mathrm{g}^{-1}\right)$} \\
\hline-26366.74 & -26378.51 & -26459.37 & -26416.79 & -26382.75 & -26325.16 \\
\hline-26365.57 & -26380.07 & -26454.61 & -26424.00 & -26370.89 & -26311.05 \\
\hline-26373.46 & -26367.32 & -26459.73 & -26422.14 & -26375.36 & -26319.94 \\
\hline-26359.00 & -26366.37 & -26464.93 & -26429.31 & -26378.21 & -26323.56 \\
\hline-26358.61 & -26377.65 & -26468.67 & -26415.27 & -26369.20 & -26326.32 \\
\hline-26374.29 & -26381.83 & -26469.26 & -26428.07 & -26369.95 & -26309.09 \\
\hline-26370.36 & $\begin{array}{l}-26366.19 \\
-26383.01\end{array}$ & & -26426.09 & & \\
\hline \multicolumn{6}{|c|}{$\left\langle\Delta_{\mathrm{c}} u^{\circ}\right\rangle^{a}\left(\mathrm{~J} \cdot \mathrm{g}^{-1}\right)$} \\
\hline$-26366.9 \pm 2.4$ & $-26375.1 \pm 2.6$ & $-26462.8 \pm 2$ & $-26423.1 \pm 2.0$ & $-26374.4 \pm 2.2$ & $-26319.2 \pm 3.0$ \\
\hline
\end{tabular}

${ }^{a}$ Mean value and given error as the standard deviation of the mean.

fully aromatic system (for CC bonds, $r_{\mathrm{opt}}=1.388 \AA$ ), ${ }^{27} r_{\mathrm{av}}$ is the average bond length of the $n$ bonds, $r_{i}$ is the bond length of bond $i$, and $\alpha$ is a normalization constant fixed to give HOMA $=0$ for a nonaromatic model system and HOMA $=1$ for a system in which all bond lengths equal $r_{\text {opt }}$. This equation is a refined model of $\mathrm{HOMA}^{28}$ where these indices can be expressed by a combination of two factors, EN (a term closely related to de-aromatization due to bond energies) and GEO (the term attributed to de-aromatization due to geometric contributions, namely, bond length alternation).

\section{Results}

Experimental Results. Table 1 lists typical experimental combustion results for each compound, where $\Delta m\left(\mathrm{H}_{2} \mathrm{O}\right)$ is the deviation from $2900.0 \mathrm{~g}$ of the mass added to the calorimeter, the mass assigned to $\epsilon$ (calor), and $\Delta U_{\Sigma}$ is the correction to the standard state. The remaining quantities are as previously described. ${ }^{17}$

The internal energy for the isothermal bomb process, $\Delta U(\mathrm{IBP})$, was calculated according to the equation

$$
\begin{gathered}
\Delta U(\mathrm{IBP})=-\left[\epsilon(\text { calor })+c_{\mathrm{p}}\left(\mathrm{H}_{2} \mathrm{O}, 1\right) \Delta m\left(\mathrm{H}_{2} \mathrm{O}\right)\right] \Delta T_{\mathrm{ad}}+ \\
\left(T_{\mathrm{i}}-298.15\right) \epsilon_{\mathrm{i}}+\left(298.15-T_{\mathrm{i}}-\Delta T_{\mathrm{ad}}\right) \epsilon_{\mathrm{f}}+\Delta U(\mathrm{ign})
\end{gathered}
$$

where $\Delta T_{\text {ad }}$ is the calorimeter temperature change corrected for the heat exchange and the work of stirring, calculated with the LABTERMO program using the Regnault-Pfaundler method applying a second-order fitting for the initial and final periods as reported by Santos et al. ${ }^{13,14}$

For each compound, the products of combustion in the experiments consist of a gaseous phase and an aqueous mixture of nitric acid for which the thermodynamic properties are known. The values of $\Delta_{\mathrm{c}} u^{\circ}$ refer to the reactions represented by

$$
\begin{array}{r}
\mathrm{C}_{8} \mathrm{H}_{9} \mathrm{O}_{2} \mathrm{~N}(\mathrm{cr})+{ }^{37} /{ }_{4} \mathrm{O}_{2}(\mathrm{~g}) \rightarrow \\
\rightarrow \mathrm{CO}_{2}(\mathrm{~g})+ \\
{ }_{9} /{ }_{2} \mathrm{H}_{2} \mathrm{O}(\mathrm{l})+{ }^{1} /{ }_{2} \mathrm{~N}_{2}(\mathrm{~g})
\end{array}
$$

Table 2 lists the individual values of $\Delta_{\mathrm{c}} u^{\circ}$, together with the mean and the standard deviation of the mean.

Table 3 lists the derived standard molar energies of combustion, $\Delta_{\mathrm{c}} U_{\mathrm{m}}^{\circ}(\mathrm{cr})$; the standard molar enthalpies of combustion, $\Delta_{\mathrm{c}} H_{\mathrm{m}}^{\circ}$ (cr); the standard molar enthalpies of formation of the crystalline solids, $\Delta_{\mathrm{f}} H_{\mathrm{m}}^{\circ}(\mathrm{cr})$; the standard molar enthalpies of sublimation, $\Delta_{\mathrm{cr}}^{\mathrm{g}} H_{\mathrm{m}}^{\circ}$, published by Monte and Hillesheim; ${ }^{10}$ and the derived standard molar enthalpies of formation in the gaseous state, $\Delta_{\mathrm{f}} H_{\mathrm{m}}^{\circ}(\mathrm{g})$, at $T=298.15 \mathrm{~K}$. In accordance with standard thermochemical practice, the uncertainties assigned to the standard molar enthalpies of combustion and formation are twice the overall standard deviation of the mean and include the uncertainties in calibration and in the auxiliary quantities used. To derive $\Delta_{\mathrm{f}} H_{\mathrm{m}}^{\circ}(\mathrm{cr})$ from $\Delta_{\mathrm{c}} H_{\mathrm{m}}^{\circ}(\mathrm{cr})$, the standard molar enthalpies of formation of $\mathrm{H}_{2} \mathrm{O}(\mathrm{l})$ and $\mathrm{CO}_{2}(\mathrm{~g})$ at $T=298.15$ $\mathrm{K},-(285.830 \pm 0.042)$ and $-(393.51 \pm 0.13) \mathrm{kJ} \cdot \mathrm{mol}^{-1}{ }^{28}$ respectively, were used. Detailed data results concerning the 
TABLE 3: Derived Standard Molar Energies of Combustion, $\Delta_{\mathrm{c}} U_{\mathrm{m}}^{\circ}$; Standard Molar Enthalpies of Combustion, $\Delta_{\mathrm{c}} H_{\mathrm{m}}^{\circ}$; Standard Molar Enthalpies of Formation in the Crystalline State, $\Delta_{\mathrm{f}} H_{\mathrm{m}}^{\circ}(\mathrm{cr})$; Standard Molar Enthalpies of Sublimation, $\Delta_{\mathrm{cr}}^{\mathrm{g}} H_{\mathrm{m}}^{\circ}{ }^{\circ 10}$ and Standard Molar Enthalpies of Formation in the Gaseous State, $\Delta_{\mathrm{f}} H_{\mathrm{m}}^{\circ}(\mathrm{g})$, at $T=298.15 \mathrm{~K}$, for the Six Isomers Studied Experimentally

\begin{tabular}{cccccc}
\hline & $\begin{array}{c}-\Delta_{\mathrm{c}} U_{\mathrm{m}}^{\circ} \\
(\mathrm{cr})\left(\mathrm{kJ}^{\circ} \mathrm{mol}^{-1}\right)\end{array}$ & $\begin{array}{c}-\Delta_{\mathrm{c}} H_{\mathrm{m}}^{\circ} \\
(\mathrm{cr})\left(\mathrm{kJ}_{\mathrm{mol}}^{-1}\right)\end{array}$ & $\begin{array}{c}-\Delta_{\mathrm{f}} H_{\mathrm{m}}^{\circ} \\
(\mathrm{cr})\left(\mathrm{kJ}_{\mathrm{mol}}{ }^{-1}\right)\end{array}$ & $\begin{array}{c}\Delta_{\mathrm{cr}}^{\mathrm{g}} H_{\mathrm{m}}^{\circ} \\
\left(\mathrm{kJ} \cdot \mathrm{mol}^{-1}\right)\end{array}$ & $\begin{array}{c}-\Delta_{\mathrm{f}} H_{\mathrm{m}}^{\circ} \\
(\mathrm{g})\left(\mathrm{kJ} \cdot \mathrm{mol}^{-1}\right)\end{array}$ \\
\hline 2a-3m-BA & $3985.7 \pm 1.3$ & $3987.6 \pm 1.3$ & $446.7 \pm 1.6$ & $107.3 \pm 1.8$ & $339.4 \pm 2.4$ \\
2a-5m-BA & $3987.0 \pm 1.3$ & $3988.8 \pm 1.3$ & $445.5 \pm 1.7$ & $110.6 \pm 1.9$ & $334.9 \pm 2.5$ \\
2a-6m-BA & $4000.2 \pm 1.2$ & $4002.1 \pm 1.2$ & $432.2 \pm 1.6$ & $116.1 \pm 2.0$ & $316.1 \pm 2.6$ \\
3a-2m-BA & $3994.2 \pm 1.2$ & $3996.1 \pm 1.2$ & $438.2 \pm 1.6$ & $127.8 \pm 2.6$ & $310.4 \pm 3.1$ \\
3a-4m-BA & $3986.9 \pm 1.2$ & $3988.7 \pm 1.2$ & $445.6 \pm 1.6$ & $119.4 \pm 2.5$ & $326.2 \pm 3.0$ \\
4a-3m-BA & $3978.5 \pm 1.4$ & $3980.4 \pm 1.4$ & $453.9 \pm 1.7$ & $122.0 \pm 2.6$ & $331.9 \pm 3.1$
\end{tabular}

TABLE 4: Total Electronic Energy Plus Zero-Point Correction $\left(E_{0}+\epsilon_{\mathrm{ZPE}}\right)$ and Enthalpic Energy Plus Thermal Correction for $T=298.15 \mathrm{~K}\left(H_{298.15} \mathrm{~K}\right)$ (in Hartrees) for the Studied Compounds ${ }^{a, b}$

\begin{tabular}{lcc}
\hline \multicolumn{1}{c}{ compound } & $E_{0}+\epsilon_{\text {ZPE }}($ hartree $)$ & $H_{298.15 \mathrm{~K}}$ (hartree) \\
\hline benzene & -232.213197 & -232.207696 \\
aniline & -287.573495 & -287.566484 \\
toluene & -271.514120 & -271.506720 \\
benzoic acid & -420.835351 & -420.827028 \\
2a-3m-BA & -515.502909 & -515.490935 \\
2a-4m-BA & -515.504199 & -515.492630 \\
2a-5m-BA & -515.501741 & -515.490564 \\
2a-6m-BA & -515.495272 & -515.483778 \\
3a-2m-BA & -515.490120 & -515.478688 \\
3a-4m-BA & -515.497448 & -515.485950 \\
3a-5m-BA & -515.497247 & -515.485432 \\
3a-6m-BA & -515.492284 & -515.480737 \\
4a-2m-BA & -515.497053 & -515.485524 \\
4a-3m-BA & -515.499926 & -515.488428
\end{tabular}

${ }^{a}$ Full geometry optimizations with the B3LYP functional at the $6-311++\mathrm{G}(\mathrm{d}, \mathrm{p})$ level of theory were performed first, followed by frequency calculations at the same theoretical level. ${ }^{b}$ Assigned energy corrections to the total energy (in hartrees/particle): $\epsilon_{\mathrm{ZPE}}=$ zero-point correction; $E_{0}=$ total electronic energy; $H_{298.15 \mathrm{~K}}=$ total electronic energy + zero-point energy (scaled to 0.9804$)+$ enthalpy correction (scaled to 0.9613 ).

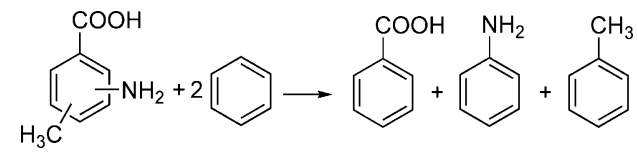

Figure 2. Separation reaction in the gas phase involving the isomers at standard conditions and $T=298.15 \mathrm{~K}$.

combustion experiments for all of the studied compounds are available as Supporting Information.

Computational Results. Table 4 presents the results for the total electronic energy plus zero-point energy correction $\left(E_{0}+\right.$ $\left.\epsilon_{\mathrm{ZPE}}\right)$ and for the enthalpic energy corrected for thermal vibration at $298.15 \mathrm{~K}\left(H_{298.15 \mathrm{~K}}\right)$, obtained from the optimized structures (absolute minimum energy) of the selected compounds.

The homodesmic reaction scheme in the gaseous phase, presented in Figure 2, was used for the calculation of $\Delta_{\mathrm{f}} H_{\mathrm{m}}^{\circ}(\mathrm{g})$ of the 10 trisubstituted compounds, and Table 5 lists these results along with the experimental values. For the calculation of $\Delta_{\text {sep }} H_{\mathrm{m}}^{\circ}(\mathrm{g})$, the following literature values (in $\mathrm{kJ} \cdot \mathrm{mol}^{-1}$ ) of $\Delta_{\mathrm{f}} H_{\mathrm{m}}^{\circ}(\mathrm{g})$ at $T=298.15 \mathrm{~K}$ were used: benzene, $+(82.9 \pm$ $0.3) ;{ }^{29}$ toluene, $+(50.1 \pm 0.3) ;{ }^{29}$ benzoic acid, $-(295.2 \pm 0.8) ;{ }^{29}$ aniline, $+(87.1 \pm 0.8) ;{ }^{29}$ 2-amino-BA, $-(296.2 \pm 1.6) ;{ }^{30}$ 3-amino-BA, $-(289.3 \pm 3.6){ }^{30}$ 4-amino-BA, $-(293.9 \pm 4.1){ }^{30}$

Figure 3 shows a typical NICS-scan plot of NICS values as a function of distance from the average ring plane from -2 to $+2 \AA$, in increments of $0.2 \AA$. The plots for all of the studied compounds are compiled in the Supporting Information. In all cases, the NICS-scan behavior shows a graphic line typical of uncharged aromatic systems. For all of the studied compounds,
TABLE 5: Experimental and Computed [B3LYP/ 6-311 $++\mathbf{G}(\mathbf{d}, \mathbf{p})]$ Values of $\Delta_{\mathrm{f}} H_{\mathrm{m}}^{\circ}(\mathrm{g})$ at $\boldsymbol{T}=298.15 \mathrm{~K}$ for the Aminomethylbenzoic Acids

\begin{tabular}{lllc}
\hline & \multicolumn{3}{c}{$-\Delta_{\mathrm{f}} H_{\mathrm{m}}^{\circ}(\mathrm{g})\left(\mathrm{kJ} \cdot \mathrm{mol}^{-1}\right)$} \\
\cline { 2 - 4 } compound & experimental & DFT & $\Delta^{a}$ \\
\hline 2a-3m-BA & $339.4 \pm 2.4$ & 339.7 & -0.3 \\
2a-4m-BA & & 344.1 & \\
2a-5m-BA & $334.9 \pm 2.5$ & 338.7 & -3.8 \\
2a-6m-BA & $316.1 \pm 2.6$ & 320.9 & -4.8 \\
3a-2m-BA & $310.4 \pm 3.1$ & 307.5 & +2.9 \\
3a-4m-BA & $326.2 \pm 3.0$ & 326.6 & -0.4 \\
3a-5m-BA & & 325.2 & \\
3a-6m-BA & & 312.9 & \\
4a-2m-BA & & 325.5 & \\
4a-3m-BA & $331.9 \pm 3.1$ & 333.1 & -1.2
\end{tabular}

${ }^{a} \Delta=\Delta_{\mathrm{f}} H_{\mathrm{m}}^{\circ}(\mathrm{g}$, experimental $)-\Delta_{\mathrm{f}} H_{\mathrm{m}}^{\circ}(\mathrm{g}$, calculated/DFT $)$.

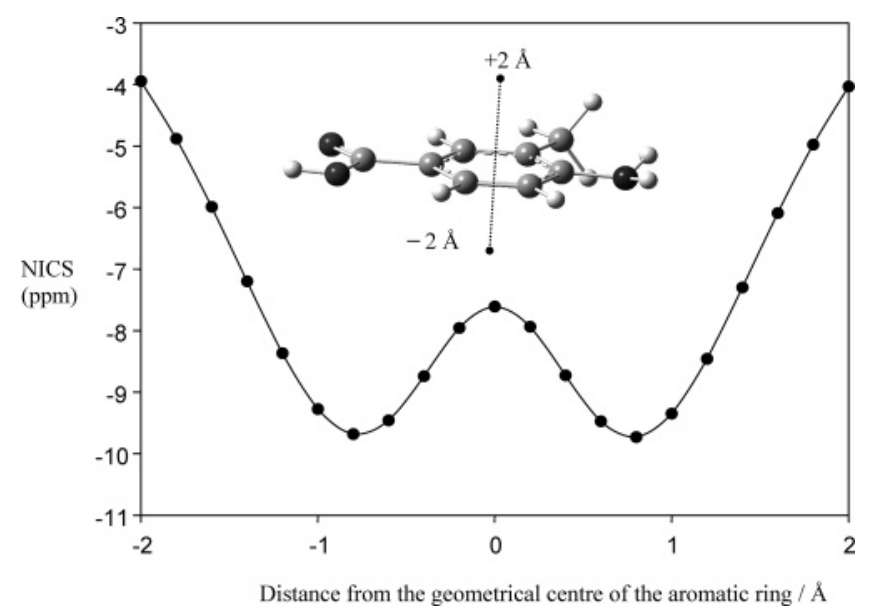

Figure 3. Typical NICS-scan diagram at the B3LYP/6-311++G(d,p) level of theory for NICS values (ppm) versus the distance from the center of the benzene ring plane $(\AA)$. This example is for the 4-amino3-methylbenzoic acid isomer.

the minimum NICS value occurs at a distance from the ring of about +0.8 and $-0.8 \AA$, rather than at about $1 \AA$, as is the case for many aromatic systems. ${ }^{6,25}$ Because NICS(1) has become a standard for the reported NICS data, NICS(1) will be used from this point onward.

\section{Discussion}

There are no previously determined values for the standard molar enthalpies of formation of aminomethylbenzoic acid isomers. The attempt to use group additivity methods to estimate the standard molar enthalpies of formation is, in the case of three different group substituents, a very difficult task because of the energetic interdependence between the position and identity of the groups.

The standard molar enthalpies of formation in the gas phase of all of the aminomethylbenzoic acid isomers, derived from 
TABLE 6: NICS(1) Values, ${ }^{a}$ HOMA Indices, $\Phi(\mathrm{Ar}-\mathrm{NHH})$ Dihedral Angles, and Experimental and Theoretical Values of $\Delta_{\mathrm{sep}} H_{\mathrm{m}}^{\circ}(\mathrm{g})$ at $T=298.15 \mathrm{~K}$

\begin{tabular}{|c|c|c|c|c|c|c|c|c|}
\hline \multirow[b]{2}{*}{ compound } & \multicolumn{2}{|c|}{ NICS (ppm) } & \multirow[b]{2}{*}{ HOMA } & \multirow[b]{2}{*}{ EN } & \multirow[b]{2}{*}{ GEO } & \multirow[b]{2}{*}{$\Phi(\mathrm{Ar}-\mathrm{NHH})(\mathrm{deg})$} & \multicolumn{2}{|c|}{$\Delta_{\text {sep }} H_{\mathrm{m}}^{\circ}(\mathrm{g})\left(\mathrm{kJ} \cdot \mathrm{mol}^{-1}\right)$} \\
\hline & $(+1)$ & $(-1)$ & & & & & experimental & DFT \\
\hline benzene & -10.2 & & 0.990 & 0.0102 & 0.000 & & & \\
\hline aniline & -9.1 & -8.9 & 0.976 & 0.0175 & 0.007 & 135.5 & & \\
\hline toluene & -9.9 & -9.8 & 0.983 & 0.0151 & 0.002 & & & \\
\hline benzoic acid & -10.3 & & 0.982 & 0.0139 & 0.004 & & & \\
\hline $2 a-3 m-B A$ & -8.2 & -8.3 & 0.839 & 0.0644 & 0.096 & 160.7 & $15.6 \pm 2.7$ & 15.9 \\
\hline $2 a-4 m-B A$ & -7.5 & -7.5 & 0.856 & 0.0593 & 0.085 & 164.0 & & 20.3 \\
\hline $2 a-5 m-B A$ & -7.8 & -7.8 & 0.864 & 0.0569 & 0.080 & 159.9 & $11.1 \pm 2.8$ & 14.9 \\
\hline $2 a-6 m-B A$ & -7.4 & -7.4 & 0.754 & 0.0910 & 0.155 & 164.3 & $-7.7 \pm 2.9$ & -2.9 \\
\hline $3 a-2 m-B A$ & -9.3 & -9.2 & 0.921 & 0.0422 & 0.037 & 135.8 & $-13.4 \pm 3.4$ & -16.3 \\
\hline $3 a-4 m-B A$ & -9.1 & -9.0 & 0.955 & 0.0285 & 0.017 & 136.6 & $2.4 \pm 3.3$ & 2.8 \\
\hline $3 a-5 m-B A$ & -8.8 & -8.6 & 0.970 & 0.0256 & 0.005 & 136.7 & & 1.4 \\
\hline $3 a-6 m-B A$ & -9.3 & -9.1 & 0.941 & 0.0370 & 0.022 & 135.3 & & -10.9 \\
\hline $4 a-2 m-B A$ & -8.3 & -8.2 & 0.912 & 0.0433 & 0.045 & 143.0 & & 1.7 \\
\hline $4 a-3 m-B A$ & -9.4 & -9.3 & 0.933 & 0.0323 & 0.034 & 142.7 & $8.1 \pm 3.4$ & 9.3 \\
\hline
\end{tabular}

${ }^{a}$ Values of NICS $(-1)$ refer to the side of the ring plane toward which the amino lone pair points, and values of NICS $(+1)$ refer to the side toward which the amino hydrogens are oriented. In the case of toluene, values of NICS $(-1)$ correspond to the side of the aromatic ring where one hydrogen atom of the methyl group forms a $90^{\circ}$ dihedral angle with the aromatic ring plane.

the computational thermochemistry at the B3LYP/6-311++G$(\mathrm{d}, \mathrm{p})$ level of theory, are in good agreement with the experimental results. The largest deviation $\left(+4.8 \mathrm{~kJ} \cdot \mathrm{mol}^{-1}\right)$ was observed for 2-amino-6-methylbenzoic acid, the isomer with the highest steric constraint around the carboxylic group. The excellent agreement between the experimental and computational thermochemistry results supports the model adopted in this work to predict $\Delta_{\mathrm{f}} H_{\mathrm{m}}^{\circ}(\mathrm{g})$ for the other four isomers.

The global energetic substituent effect can be measured by using the homodesmic reaction scheme presented in Figure 2. This is the separation reaction of the three substituents where $\Delta_{\mathrm{sep}} H_{\mathrm{m}}^{\circ}$ reflects the enthalpic interaction between all three groups in the trisubstituted compound. Negative values of $\Delta_{\mathrm{sep}} H_{\mathrm{m}}^{\circ}$ indicate an unfavorable global enthalpic interaction, positive values indicate a favorable interaction, and values near zero indicate the compensation or absence of a significant interaction among the three groups on the benzene ring relative to the three monosubstituted benzenes. The enthalpy changes can be directly related to system stability, once it is expected that the entropic term in the gas phase does not vary significantly from one structural isomer to another.

Aromaticity, and hence both NICS(1) values and HOMA indices, is more affected in some of the trisubstituted benzenes. The presence of only one group does not alter the system aromaticity much, as reported previously by Krygowski et al. ${ }^{8}$

In Table 6, the relevant results obtained in this work are compiled. Because of the asymmetry imparted by the amino group, a distinction must be made between the two sides of the ring plane. In this table, NICS $(+1)$ refers to the side of the ring toward which the two amino hydrogen atoms point, and NICS$(-1)$ refers to the side of the ring toward which the lone electron pair of the amino group is oriented. Interestingly, in some cases, NICS $(-1)$ is less negative than NICS $(+1)$, a fact that can be rationalized by the high flexibility of the nitrogen lone pair to conjugate from this side.

It is interesting to note that aromaticity is more strongly affected in those cases where the carboxylic and amino groups can interact by resonance ( $2 \mathrm{a}-\mathrm{Ym}-\mathrm{BA}$ and $4 \mathrm{a}-\mathrm{Ym}-\mathrm{BA})$. This trend is also supported by the $\Phi(\mathrm{Ar}-\mathrm{NHH})$ dihedral angles. An angle near $180^{\circ}$ indicates that the amino group is extensively conjugated with the aromatic moiety. A larger value for the angle in the cases where the $-\mathrm{COOH}$ and $-\mathrm{NH}_{2}$ groups have an ortho or para relationship was expected; in this way, the substituents can extensively conjugate for an improved reso- nance interaction, resulting in a higher delocalized electron density that leads to system stabilization.

In the ortho- $\mathrm{COOH} / \mathrm{NH}_{2}$ isomers, $\Phi(\mathrm{Ar}-\mathrm{NHH})$, the oxygento-hydrogen distance and bond topology derived by B3LYP/6$311++\mathrm{G}(\mathrm{d}, \mathrm{p})$ and the experimental energetics support the existence of an intramolecular $\mathrm{H}$ bond between the amino and carboxylic groups. Identical results were recently reported for the $-\mathrm{NH}_{2}$ group in aniline derivatives. ${ }^{31}$

Considerable system stability was found in the ortho- $\mathrm{COOH} /$ $\mathrm{NH}_{2}$ isomers, where the intramolecular hydrogen bond occurs. The compound $2 \mathrm{a}-6 \mathrm{~m}-\mathrm{BA}$ deviates from this trend because of steric constraints between the three adjacent groups. The very low HOMA index for this compound arises from the considerable distorted geometry of the ring, a factor that leads to a decrease in aromaticity. However, the amino group is extensively conjugated, showing a clear balance between the ring distortion, to relieve the steric hindrance, and the interaction by conjugation and intramolecular hydrogen bond.

The compound $3 \mathrm{a}-2 \mathrm{~m}-\mathrm{BA}$ shows distinctive steric constraints. In this case, the conjugation of the amino group with the ring is thus considered to be very small [as indicated by the smaller value of $\Phi(\mathrm{Ar}-\mathrm{NHH})$ ], which results in higher NICS(1) values and HOMA indices. It seems that this strain is mainly relieved by deformation of the substituents, leaving the geometry of the benzene ring less affected and thus preserving the system aromaticity. This fact is supported by the high HOMA indices for this compound (mainly the small GEO term). There is significant molecular stabilization in $4 \mathrm{a}-3 \mathrm{~m}-\mathrm{BA}$ due to a $-\mathrm{COOH}$ to $-\mathrm{NH}_{2}$ resonance interaction and a $-\mathrm{CH}_{3}$ to $-\mathrm{NH}_{2}$ favorable inductive interaction (brought up because of the proximity of these groups). The stabilization found in this case is quite significant as a result of the influence of the $\sigma$ - and $\pi$-donor nature of the methyl group that balances some of the ring aromaticity due to the $-\mathrm{COOH}$ to $-\mathrm{NH}_{2}$ resonance interaction. In the $3 \mathrm{a}-4 \mathrm{~m}-\mathrm{BA}$ and $3 \mathrm{a}-5 \mathrm{~m}-\mathrm{BA}$, there is no significant overall energetic stabilization. In these cases, the carboxylic and amino groups have a marginal interaction by resonance, leading to a scenario in which each group is essentially independent of each other, resulting in a weak conjugation with the ring and, therefore, in a higher ring aromaticity.

There is a reasonable correlation between NICS values and HOMA indices for the trisubstituted compounds; however, the 
presence of the three substituents adds some complexity to the system that reduces the correlation between the two aromaticity indices.

\section{Final Remarks}

The energetic study of aminomethylbenzoic acids, based on computational thermochemistry at the B3LYP/6-311++G(d,p) level of theory, is in excellent agreement with the experimental thermochemistry results. This methodology can be used to predict the energetics for this type of compound at a very low computational cost, as an alternative to group additivity methods, which fail in aromatic systems with significant interactions between groups. This is especially true in the cases of aromatic compounds with three or more substituents, where the effect on the energetics arising from the group-to-group interaction is very difficult to establish. The studied trisubstituted isomers show a significant energetic differentiation; the total influence of the three substituents is hard to preview and systematize. The energetics of systems of this type is governed by the relation between various interdependent physical aspects such as conjugation, aromaticity, and hydrogen bonds, among others.

When the amino and carboxylic groups are interacting by resonance (ortho and para), a marked stabilization is observed. The energetic stabilization, arising as a consequence of the increase in the group conjugation, is nicely followed by a decrease in the ring aromaticity derived from the NICS values and HOMA indices.

Acknowledgment. This work was supported by Fundação para a Ciência e Tecnologia (FCT) and FEDER for financial support to CIQUP. C.F.R.A.C.L. thanks FCT and the European Social Fund (ESF) under the third Community Support Framework (CSF) for the award of a Ph.D. Research Grant (SRFH/ BD/29394/2006). Thanks are also due to FCT for financial support to Project POCI/QUI/61873/2004. Dr. Bernd Schröder is acknowledged for helpful discussions.

Supporting Information Available: Additional thermochemical experimental data (Tables $\mathrm{S} 1-\mathrm{S} 7$ ). NICS values for the scan from -2 to $+2 \AA$ from the aromatic plane (Table S8). Optimized geometries ( $x y z$ format) and energies, obtained at the B3LYP/6-311++G(d,p) level, and a plot of the NICS values for the scan from -2 to $+2 \AA$ from the center of the benzene ring for each compound (Tables S9-S22). This material is available free of charge via the Internet at http://pubs.acs.org.

\section{References and Notes}

(1) Brett, C. M. A.; Thiemann, C. J. Electroanal. Chem. 2002, 538$539,215-222$.

(2) Benyoucef, A.; Huerta, F.; Vazquez, J. L.; Morallon, E. Eur. Polym. J. 2005, 41, 843-852.

(3) Nigam, M.; Seong, C. M.; Qian, Y.; Hamilton, A. D.; Sebti, S. M. J. Biol. Chem. 1993, 268, 20695-20698.

(4) Qian, Y.; Blaskovich, M. A.; Saleem, M.; Seong, C. M.; Wathen, S. P.; Hamilton, A. D.; Sebti, S. M. J. Biol. Chem. 1994, 269, 1241012413.
(5) Schleyer, P. V. R.; Maerker, C.; Dransfeld, A.; Jiao, H.; Hommes, N. J. R. J. Am. Chem. Soc. 1996, 118, 6317-6318.

(6) Stanger, A. J. Org. Chem. 2006, 71, 883-893.

(7) Krygowski, T. M. J. Chem. Inf. Comput. Sci. 1993, 33, 70-78.

(8) Krygowski, T. M.; Ejsmont, K.; Stepień, B. T.; Cyranski, M. K.; Poater, J.; Solà, M. J. Org. Chem. 2004, 69, 6634-6640. 3512 .

(9) Krygowski, T. M.; Stepień, B. T. Chem. Rev. 2005, 105, 3482-

(10) Monte, M. J. S.; Hillesheim, D. M. J. Chem. Thermodyn. 2001, $33,745-754$.

(11) Gundry, H. A.; Harrop, D.; Head, A. J.; Lewis, G. B. J. Chem. Thermodyn. 1969, 1, 321-332.

(12) Bickerton, J.; Pilcher, G.; Al-Takhin, G. J. Chem. Thermodyn. 1984, $16,373-378$ 1995.

(14) Santos, L. M. N. B. F.; Silva, M. T.; Schröder, B.; Gomes, L. J. Therm. Anal. Calorim. 2007, 89, 175-180.

(15) Coops, J.; Jessup, R. S.; van Nes, K. G. In Experimental Thermochemistry; Rossini, F. D., Ed.; Interscience: New York, 1956; Vol. 1, Chapter 3.

(16) Good, W. D.; Scott, D. W.; Waddington, G. J. Phys. Chem. 1956, $60,1080-1089$

(17) Wagman, D. D.; Evans, W. H., Parker, V. B.; Schumm, R. H.; Halow, I.; Bailey, S. M.; Churney, K. L.; Nuttall, R. L. J. Phys. Chem. Ref. Data 1982, 11, Suppl. 2.

(18) Hubbard, W. N.; Scott, D. W.; Waddington, G. In Experimental Thermochemistry; Rossini, F. D., Ed.; Interscience: New York, 1956; Vol. 1 , Chapter 5.

(19) Good, W. D.; Scott, D. W. In Experimental Thermochemistry; Skinner, H. A., Ed.; Interscience: New York, 1962; Vol. 2, Chapter 2.

(20) Wieser, M. E. Pure Appl. Chem. 2006, 78, 2051-2066.

(21) Koch, W; Holthausen, M. C. A. Chemist's Guide to Density Functional Theory, 2nd ed.; Wiley-VCH: Weinheim, Germany, 2002.

(22) Becke, A. D. J. Chem. Phys. 1993, 98, 5648-5652.

(23) Becke, A. D. Phys. Rev. A 1988, 38, 3098-3100.

(24) Lee, C.; Yang, W.; Parr, R. G. Phys. Rev. B 1988, 37, 785-789.

(25) Wong, M. W. Chem. Phys. Lett. 1996, 256, 391-399.

(26) Frisch, M. J.; Trucks, G. W.; Schlegel, H. B.; Scuseria, G. E.; Robb, M. A.; Cheeseman, J. R.; Montgomery, J. A., Jr.; Vreven, T.; Kudin, K. N.; Burant, J. C.; Millam, J. M.; Iyengar, S. S.; Tomasi, J.; Barone, V.; Mennucci, B.; Cossi, M.; Scalmani, G.; Rega, N.; Petersson, G. A.; Nakatsuji, H.; Hada, M.; Ehara, M.; Toyota, K.; Fukuda, R.; Hasegawa, J.; Ishida, M.; Nakajima, T.; Honda, Y.; Kitao, O.; Nakai, H.; Klene, M.; Li, X.; Knox, J. E.; Hratchian, H. P.; Cross, J. B.; Bakken, V.; Adamo, C.; Jaramillo, J.; Gomperts, R.; Stratmann, R. E.; Yazyev, O.; Austin, A. J.; Cammi, R.; Pomelli, C.; Ochterski, J. W.; Ayala, P. Y.; Morokuma, K.; Voth, G. A.; Salvador, P.; Dannenberg, J. J.; Zakrzewski, V. G.; Dapprich, S.; Daniels, A. D.; Strain, M. C.; Farkas, O.; Malick, D. K.; Rabuck, A. D.; Raghavachari, K.; Foresman, J. B.; Ortiz, J. V.; Cui, Q.; Baboul, A. G.; Clifford, S.; Cioslowski, J.; Stefanov, B. B.; Liu, G.; Liashenko, A.; Piskorz, P.; Komaromi, I.; Martin, R. L.; Fox, D. J.; Keith, T.; Al-Laham, M. A.; Peng, C. Y.; Nanayakkara, A.; Challacombe, M.; Gill, P. M. W.; Johnson, B.; Chen, W.; Wong, M. W.; Gonzalez, C.; Pople, J. A. Gaussian 03, revision C.02; Gaussian, Inc.: Pittsburgh, PA, 2004. 10264

(27) Krygowski, T. M.; Cyranski, M. K. Tetrahedron 1996, 52, 10255-

(28) Krygowski, T. M.; Cyranski, M. K. Tetrahedron 1996, 52, 17131722 .

(29) Cox, J. D.; Wagman, D. D.; Medvedev, V. A. CODATA Key Values for Thermodynamics; Hemisphere: New York, 1989.

(30) Pedley, J. B.; Rylance, J. Sussex-NPL Computer Analyzed Thermochemical Data: Organic and Organometallic Compounds; University of Sussex: Sussex, U.K., 1977.

(31) Szatylowicz, H.; Krygowski, T. M.; Hobza, P. J. Phys. Chem. A 2007, 111, 170-175. 